\title{
Cuerpo extraño como causa de fracaso en el sondaje vesical
}

\section{Foreign body like reason of failure in bladder catheterization}
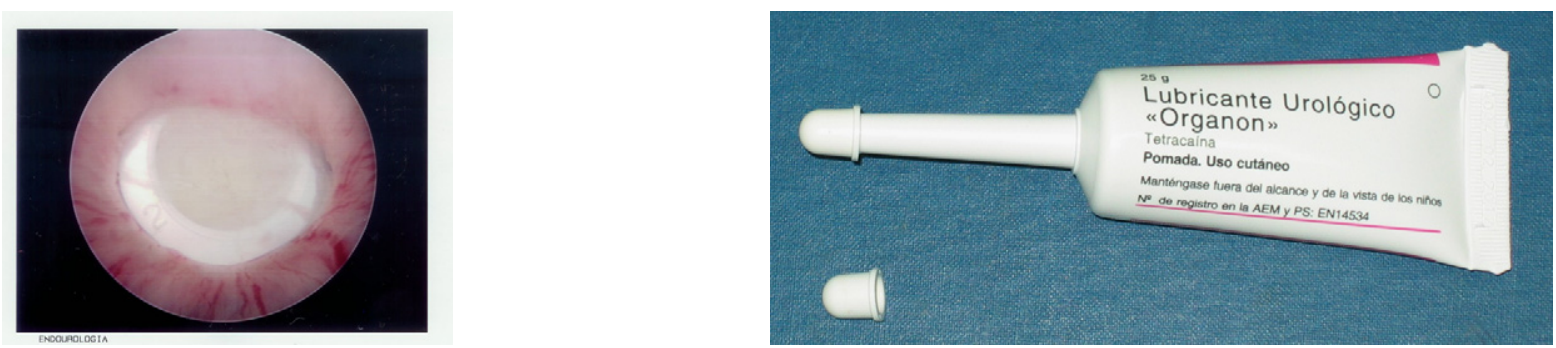

Figuras 1 y 2 - Cuerpo extraño a nivel del bulbo de la uretra (foto 1). El cuerpo extraño pertenece al tapón de un tubo de lubricante urológico (foto 2).

J. Subirá Ríos*, B. Blasco Beltrán, J. Navarro Gil,

I. Hijazo Conejos y J.G. Valdivia Uría

Servicio de Urología, Hospital Clínico Universitario Lozano Blesa, Zaragoza, España

\author{
*Autor para correspondencia. \\ Correo electrónico: kokedoc@hotmail.com (J. Subirá Ríos)
}

doi: 10.1016/j.acuro.2010.02.014

\section{Fístula colovesical secundaria a divertículos sigmoideos}

\section{Vesicosigmoidal fístula secondary to sigmoid diverticula}

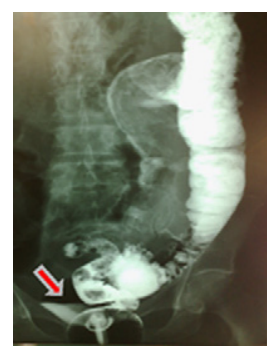

Figura 1 - Enema opaco en el que se objetivaron múltiples divertículos a nivel del colon sigmoide así como el relleno con contraste baritado de la vejiga urinaria; todo ello sugestivo de fístula colovesical.

R. Gil Ugarteburu*, I. González Rodríguez, I. Fernández García, A. Martín Huescar, L. Rodríguez Villamil y

V. Muruamendiaraz Fernández

Servicio de Urología, Hospital Cabueñes, Gijón, Asturias, España

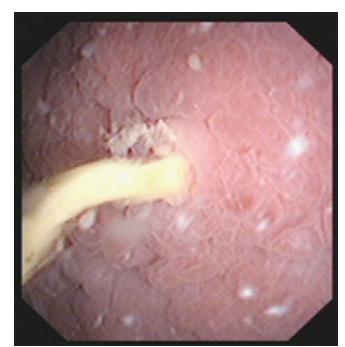

Figura 2 - Se aprecia salida de material fecaloideo al interior de la vejiga confirmando el diagnóstico.

\footnotetext{
*Autor para correspondencia.

Correo electrónico: guerrillas3@hotmail.com (R. Gil Ugarteburu)
}

doi: 10.1016/j.acuro.2010.02.015 